\title{
FORMAÇÃO DOCENTE E MULTI/ INTERCULTURALISMO: ALGUMAS REFLEXÕES
}

\author{
IRAN DE MARIA LEITÃO NUNES
}

Professora do Departamento de Educação II e do Programa de Pós-graduação em Educação da Universidade Federal do Maranhão. E-mail: iran.nunes@ufma.br

\section{MARIA NATÁLIA PEREIRA RAMOS}

Diretora do Centro de Estudos das Migrações e das Relações Interculturais. Investigadora Coordenadora do Grupo de Investigação "Saúde, Cultura e Desenvolvimento", Universidade Aberta, Lisboa. E-mail: natalia@uab.pt

\section{RESUMO}

A diversidade multifacetada, hoje presente no espaço escolar, está a exigir bases formativas que possibilitem aos professores e às professoras o convívio com a multi/interculturalidade. Quadro que nos motivou a trazer algumas reflexões sobre a temática, na busca de evidenciar sua relevância no processo de formação docente, visando compreender o multi/interculturalismo e suas implicações na educação, com base nos estudos de Candau (2008), Freire (1992, 2002), McLaren (2000), Hall (2003), Carvalho e Carvalho (2008) e Ramos (2010, 2011, 2012, 2013), bem como de evidenciar nos dispositivos legais da formação docente no Brasil referências sobre diversidades e multi/interculturalismo, na defesa de uma formação intercultural. O estudo revela que estes dispositivos legais não garantem e não significam sua efetivação nos espaços escolares e em instituições formadoras. É, portanto, premente o debate sobre estas temáticas na formação docente, compreendendo-a como uma formação de caráter intercultural, na perspectiva de transformação social, visto que a interculturalidade implica em um novo paradigma e reposicionamento metodológico, epistemológico e ético.

Palavras-chave: Formação docente. Interculturalismo. Multiculturalismo. Interculturalidade.

\section{TEACHING AND MULTI / INTERCULTURALISM TRAINING: SOME REFLECTIONS}

\begin{abstract}
The multifaceted diversity, nowadays present in the school space, is demanding formative bases that allow teachers to interact with multi/interculturality. In order to understand the multi / interculturalism and its implications in education, based on the studies of Candau (2008), Freire (1992, 2002), McLaren (2000), Hall (2003), Carvalho and Carvalho (2008) and Ramos (2010, 2011, 2012, 2013), as well as to highlight in the legal provisions of teacher education in Brazil references on diversities and multi / interculturalism, in the defense of an intercultural formation. The study reveals that these legal provisions do not guarantee and do not mean their effectiveness in school spaces and training institutions. Therefore, the debate about these themes in teacher education is urgent, understanding it as a cross-cultural formation, in the perspective of social transformation, since interculturality implies a new paradigm and methodological, epistemological and ethical repositioning.

Keywords: Teacher training. Interculturalism. Multiculturalism. Interculturality.
\end{abstract}

FORMACIÓN DOCENTE Y MULTI / INTERCULTURALISMO: ALGUNAS REFLEXIONES 


\section{RESUMEN}

Una diversidad multifacética, hoy presente en el espacio escolar, está demandando bases formativas que posibiliten a los profesores ya las profesoras la convivencia con la multi / interculturalidad. Que nos motivó a traer algunas reflexiones sobre la temática, en la búsqueda de evidenciar su relevancia en el proceso de formación docente, visando comprender el multi / interculturalismo y sus implicaciones en la educación, con base en los estudios de Candau (2008), Freire (1992, (2008) y Ramos (2010, 2011, 2012, 2013), así como de evidenciar en los dispositivos

legales de la formación docente en Brasil referencias sobre diversidades y multi/ interculturalismo en la defensa de una formación intercultural. El estudio revela que estos dispositivos legales no garantizan y no significan su efectividad en los espacios escolares y en instituciones formadoras. Por lo tanto, es urgente el debate sobre estas temáticas en la formación docente, comprendiéndola como una formación de carácter intercultural, en la perspectiva de transformación social, ya que la interculturalidad implica un nuevo paradigma y reposicionamiento metodológico, epistemológico y ético.

Palabras-clave: Formación docente. Interculturalidad. Multiculturalismo. Interculturalidad.

\section{Introdução}

De acordo com o texto oficial da Convenção sobre a Proteção e Promoção da Diversidade das Expressões Culturais , "a diversidade cultural é uma característica essencial da humanidade; constitui patrimônio comum da humanidade, a ser valorizado em benefício de todos". A Convenção evidenciou sua importância para a plena "realização dos direitos humanos e das liberdades fundamentais proclamados na Declaração Universal dos Direitos do Homem e outros instrumentos universalmente reconhecidos", e assim a define em seu Artigo 4:

"Diversidade Cultural" refere-se à multiplicidade de formas pelas quais as culturas dos grupos e sociedade encontram sua expressão. Tais expressões são transmitidas entre e dentro dos grupos e sociedades. A diversidade cultural se manifesta não apenas nas variadas formas pelas quais se expressa, se enriquece e se transmite o patrimônio cultural da humanidade mediante a variedade das expressões culturais, mas também através dos diversos modos de criação, produção, difusão, distribuição e fruição das expressões culturais, quaisquer que sejam os meios e tecnologias empregados.

Assim sendo, o convívio mais intenso e contínuo com o outro - que difere de nós, mas, como nós, têm direitos e exige respeito em seu existir diverso - está presente no seio dos Estados, das cidades e, também, das salas de aula dos diferentes níveis de ensino, em diferentes contextos.

Segundo Ramos (2011, 2013)a figura do Outro e da diversidade cultural se apresenta, hodiernamente, na figura do migrante, dos estudantes em mobilidade acadêmica, de grupos indígenas e de ciganos. 
Para a citada autora, a figura do Migrante encontra-se presente nos indivíduos que continuam a migrar, para dentro ou para fora dos seus territórios, por variados motivos (econômicos, sociodemográficos, políticos, laborais, familiares, acadêmicos e científicos, de cooperação transnacional, de desastres e catástrofes naturais), muitas vezes em processos decorrentes de violência e exclusão.

No que tange à relação diversidade cultural, migração e educação, ela está igualmente representada nos mais de três milhões de estudantes do ensino superior que se encontram fora dos seus países, os quais estão em aumento crescente, assim como os fluxos de trabalhadores qualificados, e os inúmeros docentes que partem para outros países em seus estudos de pós-graduação, em nível de Mestrado, Doutorado ou Pós-doutorado (integral ou sanduiche). E, a exemplo da mobilidade discente, podemos citar:

- Erasmus Mundus que já deu oportunidades a cerca de três milhões de estudantes universitários de frequentarem instituições de ensino superior de trinta e três países europeus, dentre os quais se inclui Portugal, e, no quadro Erasmus, mais de 1.300 alunos de fora da Europa estudaram ao abrigo deste programa;

- Ciências Sem Fronteiras, no período de 2014 a 2016 contou com 73.184 alunos/as brasileiros/as de Graduação, distribuídos em 100 Universidades de 38 países das Américas do Norte e do Sul, da Ásia, África e Europa;

- Estudante Convênio de Graduação (PEC-G) , que no período de 2000 a 2017 selecionou 7.373 estudantes de vinte e uma nações africanas, com destaque para Cabo Verde, Guiné Bissau e Angola; um total de 2.271 de vinte e três países da América Latina e Caribe, com maior participação de paraguaios, peruanos, equatorianos e hondurenhos; e 65 estudantes de quatro países asiáticos, com maioria de Timor Leste, perfazendo um total de 9.709 participantes do PEC-G em terras brasileiras.

A figura do Outro também está presente nos membros dos grupos indígenas, que correspondem a 300 milhões de pessoas, distribuídas por mais de 70 países, nos quais se inserem os 400 grupos indígenas da América Latina, (PNUD, 2016). E, no Brasil, vivem 896.900 índios ( $0,47 \%$ da população brasileira), com maior concentração nas regiões Norte (342.836) e Nordeste (232.739), divididos por 305 etnias e falantes de 274 línguas diferentes, segundo dados do Censo de 2010. (IBGE, 2012). 
O grande número de ciganos também contribui para a multiculturalidade da sociedade. Esta minoria étnica, com hábitos culturais próprios e enfrentando, em geral, condições de vida mais difíceis, maior mortalidade infantil e esperança de vida inferiorao resto da população, encontra-se espalhada por diferentes países do mundo, notadamente pela Europa, onde constituem a maior minoria étnica naquele continente (cerca de 11 milhões). Em Portugal estima-se que vivam 50.000 ciganos e, no Brasil, segundo Coradini e Souza (2014):

De acordo com dados da Pesquisa de Informações Básicas Municipais (MUNIC), do Instituto Brasileiro de Geografia e Estatística (IBGE), em 2011, foram identificados 291 acampamentos ciganos, localizados em 21 estados, sendo que os estados com maior concentração de acampamentos ciganos são: Bahia (53), Minas Gerais (58) e Goiás (38). (...) Em relação à população cigana total, estima-se que há mais de meio milhão no Brasil. Apesar desses dados da Secretaria de Políticas de Promoção da Igualdade Racial (SEPIR), não é possível dizer se são quinhentos mil ou um milhão. Nenhum dos índices do censo ajuda a recortar os ciganos, pois não há uma categoria no censo demográfico que permita contar como os ciganos se identificam. Na verdade, não existe legislação do ponto de vista de direitos especiais que leve em conta sua particularidade. (CORADINI;SOUZA, 2014, p. 206-207)

Atualmente, houve o aumento significativo da imigração de venezuelanos para o Brasil, em especial nos estados da Região Norte. Conforme estimativa divulgada pelo IBGE, cerca de 30,8 mil venezuelanos vivem aqui, dos quais 10 mil cruzaram a fronteira somente nos primeiros meses de 2018.

Convém registrar que, no Brasil, há um Outro muitas vezes invisibilizado e submetido a situações de preconceito e desrespeito: os afrodescendentes. Segundo os dados da Pesquisa Nacional por Amostra de Domicílios ( Brasileiro de Geografia e Estatística (IBGE) em 2015, apesar de os negros e pardos representarem 54\% da população brasileira, 53,2\% dos estudantes pretos ou pardos de 18 a 24 anos de idade cursavam níveis de ensino anteriores ao Superior, como o Fundamental e o Médio, enquanto apenas 29,1\% dos estudantes brancos estavam nessa mesma situação. E, apesar de o número de negros cursando a Educação Superior ter dobrado, em decorrência das Políticas de Ações Afirmativas, somente 12,8\% dessa população chegou a este nível de ensino, no referido ano.

No que tange à Comunidade LGBT, Carrara et all (2006) afirmam que as discriminações devido à sexualidade, entre as mais frequentes, são as que ocorrem entre amigos ou vizinhos, nas situações de marginalização ou exclusão na escola ou na 
faculdade, e em ambiente familiar. Elas "têm em comum o fato de ocorrerem em esferas de sociabilidade que colocam em cena pessoas íntimas (familiares e amigos) ou ao menos conhecidas (colegas, professores, vizinhos).” (CARRARA ET ALL, 2006, p. 41).

Em sendo assim, nos deparamos com uma diversidade cultural multifacetada que adentra o espaço escolar e está a exigir bases formativas que possibilitem aos professores e às professoras o convívio com a inter/multiculturalidade. Quadro que nos motivou a trazer algumas reflexões sobre a temática, na busca de evidenciar sua relevância no processo de formação docente, visando compreender o inter/multiculturalismo e suas implicações na educação, com base nos estudos de Candau (2008), Freire (1992, 2002), McLaren (2000), Hall (2003), Carvalho e Carvalho (2008) e Ramos (2010, 2011, 2012, 2013), bem como de evidenciar nos dispositivos legais da formação docente referências sobre diversidades e multi/interculturalismo, na defesa de uma formação intercultural.

Temos claro que, dada à limitação decorrente da natureza deste artigo, as reflexões sobre a temática demandariam muitas outras, para além das aqui apresentadas. Entretanto, consideramos significativo trazê-las à discussão, no desejo de contribuir para dar-lhe visibilidade. Pretendemos assim, nos somar àquelesłas que buscam trazer aos espaços formativos e às discussões acadêmicas esta temática, ressaltando a importância de sua efetiva inserção no âmbito das políticas públicas voltadas para a formação docente.

\section{Diversidades, multi/interculturalismo e formação docente nos dispositivos legais}

Consideramos necessário evidenciar que o termo multiculturalismo abarca diferentes definições e perspectivas, segundo autores como McLaren (2000) e Ramos (2010, 2011, 2012, 2013), como, também, esclarece Hall (2003):

Assim como há distintas sociedades multiculturais, assim também há "multiculturalismos" bastante diversos:

O multiculturalismo conservador segue Hume (Goldberg, 1994) ao insistir na assimilação da diferença às tradições e costumes da maioria.

O multiculturalismo liberal busca integrar os diferentes grupos culturais o mais rápido possível ao mainstream, ou sociedade majoritária, baseado em uma cidadania individual universal, tolerando certas práticas culturais particularistas apenas no domínio privado.

O multiculturalismo pluralista, por sua vez, avaliza diferenças grupais em termos culturais e concede direitos de grupo distintos a diferentes comunidades dentro de uma ordem política comunitária ou mais comunal. 
O multiculturalismo comercial pressupõe que, se a diversidade dos indivíduos de distintas comunidades for publicamente reconhecida, então os problemas de diferença cultural serão resolvidos (e dissolvidos) no consumo

privado, sem qualquer necessidade de redistribuição do poder e dos recursos.

O multiculturalismo corporativo (público ou privado) busca "administrar" as diferenças culturais da minoria, visando os interesses do centro.

O multiculturalismo crítico ou "revolucionário" enfoca o poder, o privilégio, a hierarquia das opressões e os movimentos de resistência (McLaren, 1997). Procura ser "insurgente, polivocal, heteroglosso e antifundacional" (Goldberg, 1994). E assim por diante. (HALL, 2003, p. 53).

E, encontramos em Freire (1992, p. 79) o reconhecimento da existência da multiculturalidade não como "um fenômeno espontâneo", mas "criado, produzido politicamente, trabalhado, a duras penas, na história", pois para ele:

A multiculturalidade não se constitui na justaposição de culturas, muito menos no poder exacerbado de uma sobre as outras, mas liberdade conquistada, no direito assegurado de mover-se cada cultura no respeito uma a outra, correndo risco livremente de ser diferente, sem medo de ser diferente, de ser cada uma "para si", somente como se faz possível crescerem juntas e não na experiência da tensão permanente, provocada pelo todo-poderosismo de uma sobre as demais, proibidas de ser. (FREIRE, 1992, p. 79)

O que nos remete a Candau (2008) ao evidenciar que a questão multicultural na América Latina e, em particular, no Brasil, apresenta uma configuração própria, “onde as relações interétnicas têm sido uma constante através de toda sua história, uma história dolorosa e trágica principalmente no que diz respeito aos grupos indígenas e afrodescendentes." (CANDAU, 2008, p. 17).

A citada autora distingue duas abordagens fundamentais no âmbito das questões suscitadas pelo multiculturalismo hoje: uma descritiva e uma propositiva. A primeira reconhece o multiculuralismo como uma característica das sociedades atuais, enfatizando "a descrição e a compreensão da construção da configuração multicultural de cada contexto específico" (CANDAU, 2008, p. 20). A segunda compreende o multiculturalismo não somente como um dado da realidade, mas como uma maneira de atuar, intervir e transformar a dinâmica social, a partir de diferentes abordagens, apresentadas por diversos autores, como a assimilacionista, diferencialista ou mono-culturalismo plural e o multiculturalismo interativo, ou seja, a interculturalidade. E, fazemos nossas, suas palavras ao afirmar:

A perspectiva intercultural que defendo quer promover uma educação para o reconhecimento do "outro", para o diálogo entre os diferentes grupos sociais e culturais. Uma educação para a negociação cultural, que enfrenta os conflitos 
provocados pela assimetria de poder entre os diferentes grupos socioculturais das nossas sociedades e é capaz de favorecer a construção de um projeto comum, pelo qual as diferenças sejam dialeticamente incluídas. (CANDAU, 2008, p. 23).

De acordo com Ramos (2013) a interculturalidade implica em um novo paradigma e reposicionamento metodológico, epistemológico e ético, baseadoem três vertentes estruturantes, assim sintetizadas:

Conceptual - As diferenças culturais são definidas, não como elementos objetivos com caráter estático, mas como entidades dinâmicas e interativas, que se dão sentido mútuo. A abordagem intercultural constitui outra forma de analisar a diversidade cultural, não a partir das

culturas consideradas como entidades independentes e homogéneas, mas a partir de processos e de interações;

Metodológica - A abordagem intercultural define-se como global, plural, multidimensional e interdisciplinar, de modo a dar conta das dinâmicas e da complexidade dos fenómenos sociais e a evitar os processos de categorização. Trata-se, para o investigador/educador/ interveniente, de adquirir familiaridade com o universo social sobre o qual trabalha, de compreender as representações que o animam e de se interrogar de forma reflexiva, não só sobre a cultura do outro, mas, também, e em primeiro lugar sobre a sua própria cultura;

Ética - A perspectiva intercultural tem como objetivo o conhecimento das culturas, mas, sobretudo, a relação entre elas e o Outro, implicando uma atitude de descentração (Piaget, 1970). Envolve uma reflexão sobre a forma de respeitar a diversidade individual, social e cultural, de conciliar o universal e o particular, o global e o local, de adaptação à complexidade estrutural duma sociedade e à sua conflitualidade. (RAMOS, 2013, p. 353)

Ainda, segundo a referida autora, "o intercultural implica relação, diálogo e comunicação entre as diferentes culturas, através dos indivíduos e grupos portadores dessas culturas, em situações interculturais diversas” (RAMOS, 2009, p. 18).

Cabe-nos, portanto, reconhecer os espaços educativos como elos com esta sociedade multicultural, e interrogar se e como a multi/interculturalidade está apresentada nos dispositivos legais que regem a formação docente brasileira.

Na Resolução CNE/CP No 1, de 15 de maio de 2006, que institui as Diretrizes Currriculares Nacionais para o Curso de Graduação em Pedagogia , licenciatura, encontramos citado em seu Artigo $5^{\circ}$ que o egresso do referido curso deverá estar apto a:

[...] IX - identificar problemas socioculturais e educacionais com postura investigativa e propositiva em face de realidades complexas, com vistas a contribuir para a superação de exclusões sociais, étnico-raciais, econômicas, culturais, religiosas, políticas e outras;

$\mathrm{X}$ - demonstrar consciência da diversidade, respeitando as diferenças de natureza ambiental-ecológica, étnico-racial, de gêneros, faixas geracionais, classes sociais, religiões, necessidades especiais, escolhas sexuais, entre outras. $[\ldots]$ 
Mereceu destaque, em dois parágrafos distintos, o caso de egressos indígenas ou que venham trabalhar em escolas indígenas, bem como em escolas de remanescentes de quilombos ou que se caracterizem por receber populações de etnias e culturas específicas, que deverão:

I - Promover dialogo entre conhecimentos, valores, modos de vida, orientações filosóficas, políticas e religiosas próprias à cultura do povo indígena junto a quem atuam e os provenientes da sociedade majoritária;

II - atuar como agentes interculturais, com vistas à valorização e o estudo de temas indígenas relevantes.

O Artigo seguinte menciona que a estrutura do curso de Pedagogia deve respeitar a diversidade nacional e a autonomia pedagógica das instituições, e estabelece um núcleo de estudos básicos, no qual se inserem os voltados para "diversidade cultural, cidadania, sustentabilidade, entre outras problemáticas centrais da sociedade contemporânea"; e um núcleo de aprofundamento e diversificação de estudos, voltado às áreas de atuação priorizadas pelo projeto pedagógico, que oportunizará "avaliação, criação e uso de textos, materiais didáticos, procedimentos e processos de aprendizagem que contemplem a diversidade social e cultural da sociedade brasileira".

A Resolução $\mathrm{N}^{\mathrm{o}} 2$, de $1^{\mathrm{o}}$ de julho de 2015, define as Diretrizes Curriculares Nacionais para a formação inicial e continuada em nível superior, por meio dos cursos de licenciatura, de formação pedagógica para graduados e de segunda licenciatura. Nela, encontram-se elecados em suas considerações iniciais: o respeito à liberdade e o apreço à tolerância; o respeito e a valorização da diversidade étnico-racial, entre outros. E, no parágrafo $5^{\circ}$ de seu Artigo $3^{\circ}$, estabelece dentre os princípios:

[...] II - a formação dos profissionais do magistério (formadores e estudantes) como compromisso com projeto social, político e ético que contribua para a consolidação de uma nação soberana, democrática, justa, inclusiva e que promova a emancipação dos indivíduos e grupos sociais, atenta ao reconhecimento e à valorização da diversidade e, portanto, contrária a toda forma de discriminação.

E, dentre os aspectos a serem contemplados no projeto de formação destes profissionais, conforme o parágrafo $6^{\circ}$ do supracitado artigo, encontramos "as questões socioambientais, éticas, estéticas e relativas à diversidade étinio-racial, de gênero, sexual, religiosa, de faixa geracional e sociocultural como princípios de equidade."

Esta Resolução também estabelece que "a educação em direitos humanos é uma necessidade estratégica na formação profissional do magistério e na ação educativa em 
consonância com as Diretrizes Nacionais para a Educação em Direitos Humanos”, estabelecidas por meio da Resolução $\mathrm{N}^{\circ}$ 1, de 30 de maio de 2012. Ratificando, assim, o previsto em seu Artigo $8^{\circ}$, em que ela é definida como "componente curricular obrigatório nos cursos destinados a esses profissionais", tendo dentre os sete princípios constantes no Artigo $3^{\circ}$ "o reconhecimento e valorização das diferenças e das diversidades.

Convém registrar a instituição da Lei 10.639/03 que alterou a LDB 9394/96 em seus artigos 26 e 79, tornou obrigatório o ensino da História da África e dos africanos no currículo escolar do Ensino Fundamental e Médio, e que sofreu uma alteração com a promulgação da Lei 11.645/2008, que inclui a história e a cultura indígenas:

Nos estabelecimentos de ensino fundamental e de ensino médio, públicos e privados, torna-se obrigatório o estudo da história e cultura afro-brasileira e indígena. $\S 1^{\circ} \mathrm{O}$ conteúdo programático a que se refere este artigo incluirá diversos aspectos da história e da cultura que caracterizam a formação da população brasileira, a partir desses dois grupos étnicos, tais como o estudo da história da África e dos africanos, a luta dos negros e dos povos indígenas no Brasil, a cultura negra e indígena brasileira e o negro e o índio na formação da sociedade nacional, resgatando as suas contribuições nas áreas social, econômica e política, pertinentes à história do Brasil.

A aprovação em 10/03/2004 pelo Conselho Nacional da Educação das "Diretrizes Curriculares Nacionais para a Educação das Relações Étnico-Raciais e para o Ensino de História e Cultura Afro-Brasileira e Africana". Em suas "Determinações" há o reconhecimento de que a obrigatoriedade de inclusão de História e Cultura Afro-Brasileira e Africanos currículos da Educação Básica "trata-se de decisão política, com fortes repercussões pedagógicas, inclusive na formação de professores.” (p. 17), elencando também:

Articulação entre os sistemas de ensino, estabelecimentos de ensino superior, centros de pesquisa, Núcleos de movimentos sociais, visando à formação de professores para a diversidade étnico-racial;

Introdução, nos cursos de formação de professores e de outros profissionais da educação: de análises das relações sociais e raciais no Brasil; de conceitos e de suas bases teóricas, tais como racismo, discriminações, intolerância, preconceito, estereótipo, raça, etnia, cultura, classe social, diversidade, diferença, multiculturalismo; de práticas pedagógicas, de materiais e de textos didáticos, na perspectiva da reeducação das relações étnico-raciais e do ensino e aprendizagem da História e Cultura dos Afro-brasileiros e dos Africanos;

Inclusão de discussão da questão racial como par te integrante da matriz curricular, tanto dos cursos de licenciatura para Educação Infantil, os anos iniciais e finais da Educação Fundamental, Educação Média, Educação de 
Jovens e Adultos, como de processos de formação continuada de professores, inclusive de docentes no Ensino Superior. ( p.23)

As discussões sobre a diversidade sexual no âmbito escolar emergem, no Brasil, na década de 1980, com ênfase nas abordagens sobre as questões de gênero e diversidade cultural. Em 1997os Parâmetros Curriculares Nacionais da Educação Básica (PCNs) destacaram a temática Orientação Sexual, articulada como Tema Transversal às demais áreas do conhecimento.

$\mathrm{Na}$ década seguinte, a homossexualidade também passou a se fazer presente em documentos oficiais do governo federal, dentre os quais: o Programa Nacional de Direitos Humanos (1996, 2002, 2009); Brasil Sem Homofobia: Programa de Combate à Violência e Discriminação contra GLBT e de Promoção da Cidadania Homossexual (2004); e o Plano Nacional de Promoção da Cidadania e Direitos Humanos de LGBT (2009).

O referido Plano contempla em sua Estratégia 4 - Sensibilização e mobilização de atores estratégicos eda sociedade para a promoção da cidadania e dosdireitos humanos de LGBT:

Estimular e fomentar a criação e o fortalecimento de instituições, grupos e núcleos de estudos acadêmicos, bem como a realização de eventos de divulgação científica sobre gênero, sexualidade e educação, com vistas a promover a produção e a difusão de conhecimentos que contribuam para a superação da violência, do preconceito e da discriminação em razão de orientação sexual e identidade de gênero;

Produzir e/ou estimular a confecção e a divulgação de materiais didáticos e paradidáticos e de materiais específicos para a formação de profissionais da educação para a promoção do reconhecimento da diversidade de orientação sexual e identidade de gênero, inclusive em linguagens e tecnologias que contemplem as necessidades das pessoas com deficiências;

Produzir, apoiar e divulgar pesquisas que analisem concepções pedagógicas, currículos, rotinas, atitudes e práticas adotadas no ambiente escolar diante da diversidade de orientação sexual e de identidade de gênero, para contribuir para a implementação de políticas educacionais voltadas para a superação do preconceito, da discriminação e da violência sexista e homofóbica. (BRASIL, 2009, p. 32)

Destaca-se que o Plano Nacional de Educação - PNE, em seu Artigo $2^{\circ}$, faz constar dentre suas dez diretrizes a "promoção dos princípios do respeito aos direitos humanos, à diversidade e à sustentabilidade

socioambiental", e, neste sentido, destacamos de suas Metas e Estratégias:

7.26. Consolidar a educação escolar no campo de populações tradicionais, de populações itinerantes e de comunidades indígenas e quilombolas, respeitando a 
articulação entre os ambientes escolares e comunitários e garantindo: o desenvolvimento sustentável e preservação da identidade cultural; a participação da comunidade na definição do modelo de organização pedagógica e de gestão das instituições, consideradas as práticas socioculturais e as formas particulares de organização do tempo; a oferta bilíngue na educação infantil e nos anos iniciais do ensino fundamental, em língua materna das comunidades indígenas e em língua portuguesa; a reestruturação e a aquisição de equipamentos; a oferta de programa para a formação inicial e continuada de profissionais da educação; e o atendimento em educação especial;

7.27. Desenvolver currículos e propostas pedagógicas específicas para educação escolar para as escolas do campo e para as comunidades indígenas e quilombolas, incluindo os conteúdos culturais correspondentes às respectivas comunidades e considerando o fortalecimento das práticas socioculturais e da língua materna de cada comunidade indígena, produzindo e disponibilizando materiais didáticos específicos, inclusive para os (as) alunos (as) com deficiência;

11.13. Reduzir as desigualdades étnico-raciais e regionais no acesso e permanência na educação profissional técnica de nível médio, inclusive mediante a adoção de políticas afirmativas, na forma da lei;

12.12. Consolidar e ampliar programas e ações de incentivo à mobilidade estudantil e docente em cursos de

graduação e pós-graduação, em âmbito nacional e internacional, tendo em vista o enriquecimento da formação de nível superior;

12.13. Expandir atendimento específico a populações do campo e comunidades indígenas e quilombolas, em relação a acesso, permanência, conclusão e formação de profissionais para atuação nessas populações;

18.6. Considerar as especificidades socioculturais das escolas do campo e das comunidades indígenas e quilombolas no provimento de cargos efetivos para essas escolas. (Brasil, 2014, p. 6-28)

E, em que pesem críticas a alguns aspectos destes dispositivos legais, é relevante reconhecer os avanços na luta pelos direitos humanos e respeito às diversidades que eles traduzem.

\section{Por uma formação docente intercultural}

Pelo exposto, consideramos pertinente falarmos de uma Educação Intercultural e de educarmos para a interculturalidade, o que implica em uma formação docente nesta perspectiva. Faz-se necessário, primeiramente, tornar evidente o reconhecimento do caráter etnocêntrico, homogeneizador, monocultural da educação que, em geral, se encontra presente nos espaços e cultura escolar, em suas diversas manifestações teórico-práticas. E, a partir deste, dar visibilidade a indicadores e proposições que busquem a superação deste quadro. 
Neste sentido, nos ancoramos em Candau (2008) quando afirma ser necessário aceitar e reconhecer nossas identidades culturais e nossas representações do Outro; e que há uma permanente renovação das culturas e seu processo de hibridização, concebendo a escola como espaço de crítica e produção cultural.

Para além da escola, como lócus da prática pedagógica de docentes em que estes vivenciem e estabeleçam uma educação para a interculturalidade, temos os espaços formativos, de formação inicial e continuada, nos diversos rincões brasileiros. E, ao voltarmos o olhar sobre os dispositivos legais supra elencados, percebemos que o amparo legal para que se efetive uma educação e uma formação docente na perspectiva intercultural já se encontram, implícita ou explicitamente, indicados em seus textos.

Entretanto, estes dispositivos legais não garantem e não significam sua efetivação nos espaços escolares e em instituições formadoras. Portanto, é premente o debate sobre estas temáticas na formação docente, compreendendo-a como uma formação de caráter intercultural, na perspectiva de transformação social.

Também ao nível da formação docente, Ramos (2007) destaca que o desenvolvimento de certos conhecimentos e competências poderá contribuir para melhor intervir no âmbito intercultural, assim como na mediação das relações humanas e interculturais, nomeadamente:

Desenvolvimento de competências interculturais adaptadas aos diferentes contextos de intervenção multicultural e à variedade de grupos culturais;

Uma formação que explique e contribua na compreensão da diversidade cultural e dos preconceitos e estereótipos socialmente construídos em relação às minorias e às diferenças religiosas, sociais, étnico/culturais e de género, de modo a fazer face a estas problemáticas, a combater os estereótipos e os preconceitos e a favorecer expectativas positivas em relação às minorias;

Desenvolvimento de competências linguísticas e relacionais e da comunicação com os alunos, as famílias e as comunidades;

Um melhor autoconhecimento dos profissionais, sobretudo ao nível das suas próprias identidades culturais, (e) dos seus preconceitos e estereótipos e das suas atitudes discriminatórias;

Conhecimentos psicossociais e culturais sobre os diferentes grupos culturais e sobre as representações e estilos de aprendizagem;

Uma melhor compreensão dos mecanismos psicossociais e factores sociopolíticos susceptíveis de originar a intolerância, a rejeição e o racismo. (RAMOS, 2007, p. 237). 
Nunca é demais recordar que a Declaração Universal dos Direitos do Homem (1948), no item 2 do Artigo 26. ${ }^{\circ}$, indica que:

A educação será orientada no sentido do pleno desenvolvimento da personalidade humana e do fortalecimento do respeito pelos direitos humanos e pelas liberdades fundamentais. A educação promoverá a compreensão, a tolerância e a amizade entre todas as nações e grupos raciais ou religiosos, e coadjuvará as atividades das Nações Unidas em prol da manutenção da paz.

E, em 2006 a UNESCO produziu e editou o "Guia da Educação Intercultural”, no qual propõe três grandes princípios:

1. A Educação Intercultural respeita a identidade cultural do aluno, mediante a oferta de uma educação de qualidade para todos e culturalmente relevante;

2. A Educação Intercultural desenvolve em cada aluno o conhecimento cultural, as atitudes e as competências necessárias a uma participação ativa na vida da sociedade;

3. A Educação Intercultural garante a todos os alunos a aquisição dos conhecimentos, atitudes e competências que os capacitam a contribuir para o respeito, a compreensão e a solidariedade entre indivíduos, grupos étnicos, sociais e religiosos, e nações.

Visando à redução de todas as formas de exclusão; ao aprofundamento da integração e do sucesso educativo; à promoção do respeito pela diversidade cultural; ao desenvolvimento da compreensão do outro; e ao fomento da compreensão internacional.

A Organização das Nações Unidas para a Educação, a Ciência e a Cultura - (UNESCO), junto com o Fundo das Nações Unidas para a Infância (UNICEF), o Banco Mundial, o Fundo de População das Nações Unidas (UNFPA), o Programa das Nações Unidas para o Desenvolvimento (PNUD), a ONU Mulheres e o Alto Comissariado das Nações Unidas para os Refugiados (ACNUR), organizou o Fórum Mundial de Educação 2015, em Incheon, na Coréia do Sul, entre 19 e 22 de maio de 2015.

Neste Fórum foi adotada a Declaração de Incheon para a Educação 2030, que estabelece uma nova visão para a educação para os próximos 15 anos, tendo como objetivo central: "Assegurar a educação inclusiva e equitativa e de qualidade, e promover oportunidadesde aprendizagem ao longo da vida para todos.” (UNESCO, 2016, p.15), em cujo texto afirma: 
Essa visão vai além de uma abordagem utilitária da educação e integra múltiplas dimensões da existência humana. Ela entende a educação como inclusiva e crucial na promoção da democracia e dos direitos humanos, da cidadania global, da tolerância e do engajamento civil, bem como do desenvolvimento sustentável. A educação facilita o diálogo intercultural e fomenta o respeito pela diversidade cultural, religiosa e linguística, aspectos vitais para alcançar a coesão e a justiça social. (UNESCO, 2016, p. 7)

O conteúdo dessa educação precisa ser relevante, com foco tanto no aspecto cognitivo quanto no não cognitivo da aprendizagem. Os conhecimentos, as habilidades, os valores e as atitudes necessários para que cidadãos tenham vidas produtivas, tomem decisões bem informadas e assumam papel ativo local e globalmente para enfrentar e resolver desafios globais podem ser adquiridos por meio da educação para o desenvolvimento sustentável (EDS) e da educação para a cidadania global (ECG), que inclui educação sobre paz e direitos humanos, bem como educação intercultural e para a compreensão internacional. Apesar do progresso considerável nos últimos anos, apenas 50\% dos Estadosmembros da UNESCO indicam ter, por exemplo, incluído a EDS em políticas relevantes (UNESCO, 2016, p. 29)

Nesta intencionalidade, a referida Declaração indica, dentre suas estratégias:

Garantir que o governo revise planos setoriais, orçamentos, currículos e materiais didáticos, bem como formação e supervisão de professores, para que eles não reproduzam estereótipos de gênero e promovam a equidade, a não discriminação e os direitos humanos e também fomentem uma educação intercultural. (UNESCO, 2016, p. 27)

Compreendemos que, para atender às atuais demandas quanto à temática em foco, as propostas de formação docente terão que superar o desafio de educar na perspectiva intercultural a fim de que passem a educar para interculturalidade.

Educar para a interculturalidade consiste, segundo Ramos (2007, 2009, 2011) e Carneiro (2008), também em educar os olhares sobre o mundo e sobre o Outro, aprendendo a apreciá-los. Para tanto, será necessário o exercício sistemático da escuta, ato que, para Paulo Freire (2002) transcende o sentido restrito do termo:

Escutar é obviamente algo que vai mais além da possibilidade auditiva de cada um. Escutar, no sentido aqui discutido, significa a disponibilidade de permanecer por parte do sujeito que escuta para a abertura à fala do outro, ao gesto do outro, às diferenças do outro. Isto não quer dizer, evidentemente, que escutar exija de quem realmente escuta sua redução ao outro que fala. (FREIRE, 2002, p.119). 
Assim é que, estabelecer a relação entre interculturalismo e educação, provoca reconhecermos o diálogo como exigência basilar para uma postura intercultural, notadamente na construção de uma formação docente que possibilite seu exercício. Significa, pois, adotar a perspectiva do intercultural na formação docente, como processo de diálogo, de comunicação entre pessoas ou grupos pertencentes a diferentes culturas, com vistas a promover o respeito às diversidades e a superação de preconceitos e práticas excludentes.

Para tanto, às instâncias formadoras se apresenta o desafio de, em diálogo com a comunidade, rever suas propostas de formação docente, de seus componentes curriculares e práticas pedagógicas, no sentido de atender ao já disposto em bases legais e, principalmente, ao que está a clamar na vida de tantas pessoas presentes nos espaços escolares.

\section{Considerações finais}

Retomar ao pretendido e percorrer o escrito na busca de concretizá-lo, por certo faz emergir tantas outras possibilidades de fazê-lo e abre margem a variadas críticas diante do que foi produzido. Desta maneira, costuma-se finalizar um texto sem encerrá-lo, posto que a pretensão é, também, que ele provoque outros questionamentos.

Ao trazer algumas reflexões a relação entre multi/interculturalismo e educação, pondo em relevo a formação docente, nos propomos a dar visibilidade à temática, por compreender que esta ainda carece de maiores discussões e encaminhamentos no âmbito das instâncias de formadoras.

As produções teóricas consultadas para o presente artigo, bem como outras existentes, demonstram que há uma caminhada nem tão recente e profícua sobre a matéria, no entanto, é indispensável que sejam mais amplamente divulgadas e discutidas, fundamentando uma prática pedagógica a ser redimensionada visando educar para a interculturalidade.

Formar pedagogos/as e licenciados/as das diversas áreas na perspectiva da interculturalidade em um país de clara multifacetada cultura, apresenta-se, para nós, como prioritário para e na transformação do quadro excludente e preconceituoso ainda presente nos espaços educativos, ressaltando a necessidade de garantir os avanços e os direitos já conseguidos. 
Portanto, reconhecer o multi/intercultural em nosso cotidiano requer também compreender sua riqueza e reforçar o respeito e a solidariedade entre as diferentes culturas, promovendo práticas e oportunidades de uma educação para a interculturalidade. E, assim, nos abrirmos ao que Paulo Freire nos provocou ao longo de sua vida e de suas obras: "assumir-se como ser social e histórico, como ser pensante, comunicante, transformador, criador, realizador de sonhos, capaz de ter raiva porque capaz de amar." (FREIRE, 2002, p 23).

\section{Referências}

BRASIL. Decreto n. 7.612, de 17 de novembro de 2011. Institui o Plano Nacional dos Direitos da Pessoa com Deficiência - Plano Viver sem Limite. Disponível em: <http://www.planalto.gov.br/_ccivil_03/_Ato2011-2014/2011/Decreto/D7612.htm>. Acesso em: 5 jun. 2018. Não paginado.

BRASIL, PNE Disponível em: http://www.planalto.gov.br/ CCIVIL_03/_Ato20112014/2014/Lei/L13005.htm Acesso em: 29 jun. 2018.

CANDAU, V. M. Multiculturalismo e educação: desafios para a prática pedagógica. In: MOREIRA, Antonio Flávio; CANDAU, Vera Maria. (Orgs). Multiculturalismo: diferenças e práticas pedagógicas. Petrópolis, RJ: Vozes, 2008.

CARNEIRO. R. Educação Intercultural. Colecção Portugal Intercultural. Estudos Históricos sobre o Intercâmbio de Povos e Culturas. Volume IV - Desafios à Identidade. Lisboa: Alto Comissariado para a Imigração e Diálogo Intercultural, 2008. Disponível:http://www.oi.acidi.gov.pt/

modules.php?name=Content $\&$ pa $=$ showpage $\&$ pid=44. Acesso em: 09 nov. 2012.

CARVALHO, F. \& CARVALHO, F.A. A Experiência de Formação de Professores Indígenas do Núcleo Insikiran da Universidade Federal de Roraima. In: MATO, Daniel (coord.) Diversidad Cultural e interculturalidad en educacíon superior. Experiencias en America Latina y el Caribe (IESALC). Caracas: Instituto Internacional de la UNESCO para la Educación Superior en América Latina y el Caribe (UNESCO-IESALC), 2008 , p. 157- 166. http://ensinosuperiorindigena.wordpress.com/cosmologia/ interculturalismo/ Acesso em: 15 de Ago. 2018

CARRARA, S.; FACCHINI, R.;SIMÕES,J. ; RAMOS, S. Política, direitos, violência e homossexualidade: pesquisa $9^{\text {a }}$ parada do orgulho GLBT - São Paulo 2005. Rio de Janeiro: CEPESC, 2006.

CORADINI, L.; SOUZA, V. de A. - Os ciganos do Rio Grande do Norte: caminhos e trânsitos Sociologia, Revista da Faculdade de Letras da Universidade do Porto Número temático - Ciganos na Península Ibérica e Brasil: estudos e políticas sociais, 2014, pág. 205-229 
FREIRE, P. Educação na Cidade. 6. ed. São Paulo: Cortez, 2005.

D’ Água, 1997.

Professora sim, tia não: cartas a quem ousa ensinar. 8. ed. São Paulo: Olho de Nossa Época).

Política e Educação. 2.ed. São Paulo: Cortez, 1995.v.23.(Coleção Questões

Pedagogia da Autonomia: saberes necessários à prática educativa. 31.ed. São Paulo: Paz e Terra, 2002.

Pedagogia do Oprimido. 46.ed. Rio de Janeiro: Paz e Terra, 2005.

- Pedagogia da Esperança: um reencontro com a pedagogia do Oprimido.Rio de Janeiro: Paz e Terra, 1992.

Extensão ou Comunicação. Rio de Janeiro: Paz e Terra,1988. (2002)

Pedagogia da Indignação: cartas pedagógicas e outros escritos.São Paulo:UNESP, 2000.

Educação como prática da liberdade. Rio de Janeiro: Paz e Terra, 1980.

HALL, S. (2006). Da diáspora: identidades e mediações culturais. Stuart Hall. Organização Liv Sovik;Tradução Adelaine La Guardia Resende et all. Belo Horizonte: Editora UFMG; Brasilia: Representação da UNESCO no Brasil, 2003.

MCLAREN, P. Multiculturalismo Crítico. São Paulo: Cortez. 1997.

- Impensar el Caucasismo, Repensar la Democracia: ciudadanía crítica en gringolandia. IN: Multiculturalismo Revolucionario: Pedagogías de disensión para el nuevo milênio. Madri, España:Siglo Veintiuno de España editores, 1998. (238-295)

Programa de las Naciones Unidas para el Desarrollo (PNUD). Informe sobre Desarrollo Humano 2016. Desarrollo humano para todas las personas. 1 UN Plaza, Nueva York, NY 10017, Estados Unidos, 2016

RAMOS, N. Espaços e tempo (s) das culturas do mar: perspectivas e desafios sociais, interculturais e de saúde. In Serafim, J. F.; Santana, S. R. Lima de (Orgs.) Representações do Meio Ambiente - Clima, Cultura, Cinema. Salvador: EDUFBA, 2012, p. 87-107.

Educar para a interculturalidade e cidadania. Princípios e desafios. In ALCOFORADO, L. et al. Educação e formação de adultos. Políticas, práticas einvestigação. Coimbra: Imprensa da Universidade de Coimbra, 2011, p. 189-200.

Diversidade cultural, educação e comunicação intercultural - políticas e estratégias para a promoção do diálogo intercultural. Revista Educação em Questão. V. 
34, n. 20, jan./abr, p. 9-32,2009. Disponível: www.revistaeduquestao.educ.ufrn.br. Acesso em: 10 ago. 2011.

A diversidade cultural da cidade: problemas e desafios. In RUBIM, L; MIRANDA, N. (Orgs.). Transversalidades da cultura. Salvador: EDUFBA, 2008, p. 133-179.

Sociedades multiculturais, interculturalidade e educação. Desafios pedagógicos, comunicacionais e políticos. Revista Portuguesa de Pedagogia, ano 41-3, p. 223-244, 2007.

Conflitos interculturais no espaço europeu... In: The overarching issues of the european space: the territorial diversity of opportunities in a scenario of crisis. Porto: Faculdade de Letras da Universidade do Porto. 2014, p. 225-245

UNESCO, Guidelines on Intercultural Education, 2006: Disponível em: http://eric.ed.gov/ERICDocs/data//ericdocs2sql/content_ storage_01/0000019b/80/33/c2/cf.pdf. Acesso em: 29 jun. 2018.

UNESCO, Educação 2030. Declaração de Incheon: Rumo a uma educação de qualidadeinclusiva e equitativa e à educação ao longo da vida para todos, 2016. Disponível em: https://unesdoc.unesco. org/ark:/48223/pf0000243278_por. Acesso em: 29 jun. 2018.

VASCONCELOS, M.; RIBEIRO, J.; COSTA, E. Dados oficiais sobre os povos romani (ciganos) no Brasil-2013Edição: 1 Brasília -DF AMSK/Brasil, 2013.

\section{Notas}

I Assinada em Paris, em 20 de outubro de 2005, e promulgada pelo Brasil por meio do Decreto $\mathrm{N}^{\mathrm{o}} 6.177$, de $1^{\circ}$ de agosto de 2007.

II O Erasmus Mundus é um Programa de Ensino Superior financiado pela Comissão Europeia, com o objetivo de promover a cooperação interinstitucional entre Instituições de Ensino Superior europeias e brasileiras, para estudantes de graduação, pesquisadores e membros do staff

III Programa é uma iniciativa dos Ministérios da Ciência, Tecnologia e Inovação e da Educação, visando promover a consolidação, expansão e internacionalização da ciência, tecnologia, da inovação e da competitividade brasileira por meio do intercâmbio e da mobilidade internacional.

IV Programa desenvolvido pelos Ministérios das Relações Exteriores e da Educação, em parceria com universidades públicas e particulares, oferece oportunidades de formação superior a cidadãos de países em desenvolvimento com os quais o Brasil mantém acordos educacionais e culturais. È regido pelo DECRETO Presidencial no 7.948, de 12 de março de 2013. (Site oficial do MEC).

V Os povos indígenas compõem cerca de $5 \%$ da população mundial, e $15 \%$ das pessoas que vivem em situação de pobreza. (PNUD, 2016). 
VI Parte do reconhecimento de que vivemos em uma sociedade multicultural, na qual não existe igualdade de oportunidade para todos/as, favorecendo a que todos/as se integrem na sociedade e sejam incorporados à cultura hegemônica. (CANDAU, 2008).

VII Parte da afirmação de que ao enfatizar a assimilação, nega-se ou silencia-se a diferença. Portanto, enfatiza o reconhecimento das diferenças, garantindo as expressão das diferentes identidades, seu acesso a direitos sociais e econômicos, e espaços próprios e específicos para se expressarem com liberdade. (CANDAU, 2008).

VIII Lei $\mathrm{n}^{\circ} 13.005$, aprovada em 25 de junho de 2014, com vigência por 10 (dez) anos, a contar de sua publicação, com vistas ao cumprimento do disposto no art. 214 da Constituição Federal.

O Fórum contou com mais de 1.600 participantes de 160 países, incluindo cerca de 120 ministros, chefes e membros de delegações, líderes de agências e funcionários de organizações multilaterais e bilaterais, além de representantes da sociedade civil, da profissão docente, do movimento jovem e do setor privado. 